\title{
Indonesian Idol: A Fabricated Reality for Commodification
}

\author{
Nuril Ashivah Misbah \\ Staff Pengajar Fakultas Ilmu Sosial dan Ilmu Politik \\ Universitas Wiraraja, Sumenep \\ Email: ivamisbah@gmail.com
}

\begin{abstract}
Abstrak
Maraknya reality program mampu mengubah konstelasi ekonomi industri televisi. Perubahan konstelasi ini paling besar dapat dilihat dari pemasukan yang bisa diraup oleh industri televisi dari reality program. Pertanyaan yang diajukan dalam kajian ini adalah bagaimana proses komodifikasi 'realitas' dalam reality program? Hasil kajian menunjukkan Indonesian Idol dikonstruksi sedemikian rupa agar sesuai dengan standar market price dan menghasilkan marketable product, atau ketika logika ekonomi media. Untuk mencapai standar tersebut, terjadi proses komodifikasi, di mana rating menjadi ukuran/patokan. Komodifikasi content itu dilakukan melalui beragam cara, diantaranya setting panggung, pilihan juri, ataupun format lomba dalam Indonesian Idol. Keseluruhan komodifikasi itu pada akhirnya menguntungkan industri televisi, dalam hal ini RCTI dan lebih-lebih Fremantle Media yang merupakan penggagas program siaran tersebut.
\end{abstract}

Kata Kunci: Reality show, Indonesian idol, komodifikasi

\begin{abstract}
Reality program today has shifted the economic constellation of television industry. It is mainly portrayed by the increased of television industry profit which is generated from reality programs. The popularity of reality program is established based on assumption about the nature of these shows that is believed to be natural, real, familiar, and depicts common people. This article aims to problematize that assumption by referring to logic of media economics. This background leads to questions on how commodification process of 'reality' in reality program. This study analyzes Indonesian Idol as case study using political economy media approach. The study shows that Indonesian Idol is constructed in many ways to adjust the market standards and to appear as marketable product which is compatible with rating demand. Content commodification of Indonesian Idol has been done in many and certain means, such as stage setting, the panel, and contest format. Eventually, those commodification benefited television industry, both RCTI and, particularly, Fremantle Media, the original program owner.
\end{abstract}

Keywords: reality show, indonesian idol, commodification of content 


\section{Latar Belakang}

Popularitas reality program dalam satu dekade terakhir begitu tinggi, termasuk di Indonesia. Merujuk catatan Hill (2005) maraknya reality program mampu mengubah konstelasi ekonomi industri televisi. Perubahan konstelasi ini paling besar dapat dilihat dari pemasukan yang bisa diraup oleh industri televisi dari reality program. Dengan popularitas yang tinggi, tentunya, rating pun tinggi, dan secara otomatis pemasukan yang diperoleh dari program tersebut pun tinggi. Dalam kaitan ini, Hill mengemukakan bahwa popularitas reality program di Amerika untuk beberapa program seperti American Idol, misalnya, mampu mencapai angka 50\% untuk market share-nya, yang berarti separuh masyarakat Amerika menonton program ini di setiap kali penayangannya. Beberapa program lain seperti Big Brother, Joe Millionaire, dan The Big Loser juga mendapatkan penonton yang besar.

Fenomena maraknya reality program ini terjadi tidak hanya di Amerika, dalam catatan Hill (2005: 4), reality program merupakan genre yang populer di seluruh dunia. Dia memberikan gambaran di negara-negara Eropa, Amerika Latin, Afrika, dan Australia. Meski data Hill tidak mencakup Asia, tapi dapat dipastikan reality $T V$ merupakan fenomena yang juga marak di Asia, termasuk Indonesia. Secara sederhana, hal ini bisa dilihat dari jumlah program bergenre reality $T V$ di tiap-tiap stasiun televisi yang merentang mulai dari gameshow, talent show, talkshow, sport, charity, cooking, dan travelling. Di Indonesia, beberapa reality misalnya Indonesian Idol (RCTI), Main Kata (Global TV), Bosan jadi Pegawai, ala Chef, Ethnic Runaway, Celebrity on Vacation (Trans TV), Bolang, Jejak Petualang, Citacitaku (Trans7), dan masih banyak lagi.

$$
\text { Dalam analisisnya, Hill }
$$

menyatakan tingginya popularitas reality program salah satunya dikarenakan program ini ditonton oleh audiens berusia muda yang memiliki range paling luas dari range usia lainnya, yaitu antara usia 15 tahun - 35 tahun. Dengan range seluas ini, menjadi wajar reality program mencapai popularitas yang tinggi. Popularitas di kalangan penonton ini kemudian ditunjang juga oleh para pengiklan yang menjadikan usia muda sebagai target utama dari banyak produk sehingga tayangan reality program terus menjadi pilihan bagi para produser televisi sebagai tawaran utama di banyak channel.

One of the reasons the reality genre has been so powerful in the television market is that is appeals to younger adults in particular. For example, reality gameshows and talent shows in the USA are especially popular with 'young viewers who have watched reality show in far bigger numbers thatn anything else on television and are the consumers most coveted by advertisers' (Hill, 2005: 5). 
Masih berdasarkan pada analisis Hill (2005), popularitas yang mampu dicapai oleh program-program ber-genre reality ini pada dasarnya bukan merupakan kesengajaan, tapi lebih kepada 'kebetulan yang menguntungkan'. Tuntutan untuk membuat program yang lebih murah sebagai efisiensi ekonomi menjadi semacam pijakan awal bagi lahirnya reality program. Dibandingkan dengan program drama yang kala itu menjadi hidangan utama televisi, reality program hanya membutuhkan seperempat dari biaya produksi satu jam drama. Ini karena reality program hanya membutuhkan tim produksi kecil dengan sangat sedikit scriptwriter dan hampir tidak menggunakan aktor/aktris profesional dalam tiap produksinya. Secara kebetulan, meskipun reality program awalnya dibuat karena pertimbangan menekan biaya produksi, ternyata reality program mampu memberikan pemasukan yang besar bagi industri televisi karena ia pun ternyata begitu populer di kalangan penonton. Oleh karena itu, reality program menjadi sangat menarik bagi para produsen televisi.

Keberhasilan reality program yang mampu menimbulkan perubahan ekonomi dalam industri televisi hingga kemudian me-restrukturasi bisnis televisi. Restrukturasi berupa pengurangan terhadap jatah program-program berskrip panjang dan menambahkan jumlah jam tayang dengan program-program reality.
The ratings success of network reality series has ensured that some television executives are ready to embrace plans for a radical restructuring of the network business. Such restructuring may involve the provision of new programming fifty-two weeks of the year, a reduction in scripted series by Hollywood studios, and an increase in product placement within programmes (Hill, 2005: 6).

Pada perkembangan selanjutnya, reality program menjadi pilihan yang hampir selalu dipilih oleh pada produser di dunia pertelevisian dalam membuat sebuah program baru. Luasnya ragam kategori yang tergolong ke dalam reality program pun menjadi sebuah kelebihan dari genre ini sehingga para produser memiliki pilihan yang luas dalam memformulasi sebuah program baru. Ada banyak ragam diantaranya talent show, game show, talk show, sport, charity, atau lainnya.

Jika reality program menjadi pilihan populer di kalangan produsen dan eksekutif industri televisi karena secara ekonomi sangat menjanjikan, maka pertanyaannya kemudian adalah apa sebenarnya yang membuat reality program populer di kalangan audiens? Menyadur keterangan Chief Execuive Freemantle Media, Catherine Mackay, "reality shows are a lot cheaper to make, and yet they are getting just as many ayeballs in many instances and, sometimes, even more because of the event nature of these shows" (dalam Hill, 
2005: 7). Dari pernyataan Mackay tersebut, yang penting untuk digarisbawahi terkait pilihan audiens atas program reality show adalah 'even more because of the event nature of these shows'. Sifat reality program sendiri jelas merupakan program yang berbasis pada kenyataan dan tidak berpatokan pada sekenario yang telah ditentukan berdasar alur cerita tertentu. Dengan kata lain, reality program adalah program yang menghadirkan realitas kepada penonton dan tidak bersifat fiktif. Hal inilah yang kemudian menjadikan reality program "seolah" dekat dengan penonton.

In many ways, the classification of reality $T V$ in relation to 'reality' is connected with audience understanding of the performance of non-professional actors in the programmes, and the ways 'real people' play up to the cameras (Hill, 2005: 54).

Perasaan dekat dengan orang yang berada dalam program karena merasa sama-sama orang biasa (common people), atau perasaan dekat dengan setting atau tempat atau suasana yang digambarkan dalam kamera, merupakan rasa yang menciptakan proximity dari para penonton terhadap reality program. Sifat reality program yang mampu menciptakan kedekatan itulah yang bisa ditangkap sebagai alasan mengapa reality program menjadi begitu populer di kalangan penonton televisi (audiens). Permasalahannya kemudian, bagaimana kemudian realitas tersebut ditampilkan dalam media agar kedekatan yang dirasakan penonton dapat terus-menerus direproduksi sehingga di sisi lain keuntungan secara ekonomi dari reality program dapat terpenuhi dan terus meningkat? Upaya tersebut tentu saja harus sejalan dengan misi ekonomi media, yaitu dengan logika industri dan bisnis operation (Alexander, 2004: 5). Singkatnya, upaya tersebut adalah upaya untuk menghadirkan 'realitas' yang 'layak jual'. Untuk mencapai realitas yang layak jual tersebut, ada proses komodifikasi atas realitas tersebut. Hal inilah yang ingin dijawab dalam tulisan ini, yakni bagaimana proses komodifikasi 'realitas' dalam reality program?

Tanpa bertujuan untuk menjawab proses komodifikasi realitas dalam seluruh program reality, tulisan ini akan mengambil kasus pada satu program reality yang sedang marak di Indonesia, yaitu Indonesian Idol. Sebuah talent show yang mencari orang dengan bakat menyanyi terbaik. Di tiap musimnya, Indonesian Idol selalu memiliki iklan utama atau sponsor utama. Nantinya, analisis akan fokus pada bagaimana realitas ditampilkan dalam program Indonesian Idol sebagai bentuk komodifikasi terhadap realitas itu sendiri dan kaitannya dengan aspek ekonomi politik lembaga media yang menyiarkannya. 
Komodifikasi Isi (Media): Sell Everything, Everything is Sold

Golding dan Murdock (1992: 18) melihat bahwa produk media merupakan hasil konstruksi yang disesuaikan dengan dinamika ekonomi yang sedang berlangsung dan struktur-sturktur dalam institusi yang menyokong berputarnya roda institusi media. Menurut kedua penulis ini, berita yang disajikan pada masyarakat disusun berdasarkan relasirelasi yang ada antara pemilik insitusi pers (owner), editor, jurnalis, dan sumber berita. Dari apa yang disampaikan Golding dan Murdock tersebut, dapat dikatakan bahwa dalam produksi pesan (isi) media ada relasi-relasi yang terjalin mulai dari proses produksi hingga distribusi pesan yang melibatkan para pekerja, teknologi, audiens, serta kepentingan industri media sekaligus kepentingan pemiliknya. Untuk melihat dan membongkar relasi dalam setiap proses yang terjadi dalam media, pendekatan ekonomi politik adalah salah satu alat dalam membongkar relasi-relasi tersebut.

Menurut Golding dan Murdock (1992: 18), sebagai sebuah pendekatan kritis, ekonomi politik selalu berada dalam hubungan saling pengaruhmempengaruhi antara lembaga ekonomi dan politik, juga kehidupan sosial dan kultural. Di sinilah, terjadi tarik-menarik kepentingan baik dalam distribusi kekuasaan (display of power), kontrol, orientasi ekonomi media, dan ideologi berlangsung dalam setiap proses produksi, distribusi, dan konsumsi. Relasi kuasa ini yang kemudian coba dibongkar melalui pendekatan ekonomi politik, yakni bagaimana relasi kuasa yang terjalin dalam media di setiap prosesnyaproduksi, distribusi, konsumsimempengaruhi isi media dan menentukan bagaimana isi (media content) tersebut nantinya bekerja sesuai logika industri.

Sebagaimana Golding dan Murdock, Vincent Moscó (2009: 24) juga menekankan persoalan relasi kuasa dalam definisinya tentang ekonomi politik. Mosco, dalam hal ini, mengemukakan, "the study of the social relation, particularly the power relation, that mutually constitute the production, distribution, and consumption of resources". Lebih lanjut, Moscó mengemukakan "a specific set of social realations organized around power or the ability to control other people, process, and things, even in the face of resistance". Dengan demikian, menurut Moscó, seorang analis ekonomi politik akan mampu melihat bentuk-bentuk pergeseran dari kontrol tersebut di seputar proses produksi, distribusi, dan distribusi.

Salah satu cara dalam melihat relasi kuasa dalam proses produksi, distribusi, dan konsumsi dalam media adalah melalui analisis komodifikasi dalam praktik media. Komodifikasi sendiri secara sederhana disebut Moscó 
sebagai proses berubahnya nilai guna (use values) ke nilai tukar (exchange values).

Commodification refers to the process of turning use values into exchange values, of transforming products whose value is determined by their ability to meet individual and social needs into products whose value is set by their market price (Moscó, 2009: 132).

Dari definisi Moscó di atas, didapatkan kata kunci dari komodifikasi, yaitu individual needs yang berarti use values dan market price berarti exchange values. Ketika sebuah produk tidak lagi ditentukan oleh kegunaan dari sebuah produk yang disesuaikan dengan kebutuhan individu atau kebutuhan sosial, tapi lebih dikendalikan oleh pasar yang membentuk pseudo-needs, maka komodifikasi telah terjadi.

Moscó membagi tiga bentuk komodifikasi dalam komunikasi (2009: 133-141). Pertama, komodifikasi isi (content), dimana pesan (teks media) diproduksi dengan menggunakan simbolsimbol sebagai arena representasi hingga mewujud dalam bentuk produk yang dapat dipasarkan. Kedua, komodifikasi audiens, dimana audiens dijadikan komoditas yang "dijual" kepada para pengiklan. Ketiga, komodifikasi pekerja, dimana keahlian dan jam kerja para pekerja dijadikan komoditas dan dihargai dengan gaji. Dalam tulisan ini, penulis akan menggunakan kategori pertama yang dibuat Moscó, yaitu komodifikasi isi (content).

Merujuk Moscó, setiap analis ekonomi politik dalam mengkaji bentuk komodifikasi komunikasi, hampir selalu dimulai dengan komodifikasi content. Komodifikasi content menurut Moscó (2009: 133) akan selalu, “...involves transforming messages, ranging from bits of data to systems of meaningful thought, into marketable products". Dengan kata lain, teks media dikonstruksi sedemikian rupa sehingga teks tersebut mampu bertindak sebagai sebuah produk yang layak jual di pasaran, yang mampu mendatangkan keuntungan dan surplus value bagi media yang menyiarkannya. Proses perubahan teks media menjadi exchange value ini akan selalu melibatkan proses yang kompleks dari relasi-relasi sosial yang ada termasuk pekerja, konsumen (audiens), dan modal.

Pada akhirnya, media content (teks) memang seolah hanya menjadi produk semata. Namun, Moscó sendiri memberi catatan bahwa teks media berbeda dengan komoditas lain, dan cenderung spesial karena ia merupakan powerful comodity. Ini karena ia mengandung simbol-simbol dan citracitra yang maknanya mampu membentuk kesadaran tertentu pada audiens yang menerimanya sehingga teks media mampu menjadi arena potensial tempat terjadinya komodifikasi. 
Seluruh proses komodifikasi yang dijelaskan Moscó dan kembali pada apa yang disampaikan Golding dan Murdock sebelumnya, dapat ditarik sebuah premis bahwa proses komodifikasi terjadi karena menyesuaikan dengan kepentingan industri media, yang berarti bahwa sesuai dengan kepentingan dari si pemilik media. Dengan kata lain, kebijakan yang diambil pemilik akan sangat menentukan proses komodifikasi yang terjadi dalam media. Oleh karena itu, penting untuk melihat bagaimana kepentingan owner RCTI sebagai lembaga media yang menyiarkan Indonesian Idol dan hubungannya dengan Fremantle Media sebagai perusahaan produser program Idol.

\section{The Manipulation of Reality}

Dalam Indonesian Idol, realitas yang dihadirkan merupakan sebuah kompetisi yang diawali dari audisi hingga spektakuler show di mana masing-masing peserta dieliminasi satu-persatu sesuai dengan vote yang tiap peserta peroleh berdasar SMS yang masuk. Di setiap proses kompetisi, akan ada juri yang menjadi penilai dan kritikus terhadap penampilan yang dibuat semua peserta. Komentar juri biasanya berpengaruh terhadap perolehan vote SMS, apakah menjadi lebih tinggi atau lebih rendah.

Jika kita perhatikan penjelasan Hill (2005: 41) tentang reality program, yang menyatakan, "there are a variety of styles and techniques associated with reality $T V$, such as non-profeessional actors, unscripted dialogue, surveillance footage, hand-held cameras, seeing events unfold as they are happening in front of the camera", maka Indonesian Idol di satu sisi tidak dapat sepenuhnya dikatakan sebagai tanpa script dan benarbenar memperlihatkan events unfold as they are happening in front of the camera. Ini karena pada dasarnya, konsep audisi, kompetisi di setiap minggu, eliminasi, juri, dan vote SMS merupakan sebuah konstruksi atas realitas. Yakni membentuk sebuah realitas sehingga sesuai dengan bentuk "talent show" sebagai konsep acara dari Indonesian Idol. Meski di sisi lain, Indonesian Idol juga menghadirkan karakternya sebagai sebuah reality program misalnya tokohtokoh yang dihadirkan dalam program adalah bukan selebritis (orang biasa) yang memerankan dirinya sendiri serta membawa identitasnya sendiri. Ia bukan tokoh rekaan dengan identitas yang sengaja dibuat untuk memenuhi alur cerita yang juga telah ditentukan. Peserta berasal dari seluruh Indonesia yang diseleksi melalui proses audisi di beberapa kota dan mereka belum pernah masuk ke dalam industri musik Indonesia. Selain itu, dalam praktiknya, apa yang ditayangkan di televisi itulah yang sedang berlangsung. Hanya saja, seperti yang telah disinggung di atas, konsep kompetisi sendiri merupakan sebuah realitas yang dikonstruksi berdasarkan standar program pencarian bakat dan faktor lainnya. 
Analisis di atas sedikit banyak sesuai dengan apa yang diungkapkan Ron Simon (2005: 179-180). Secara sederhana, Simon membedakan reality program sebagai lawan dari program hiburan yang mainstream di televisi yang biasanya selalu berdasar pada script dan bintang/selebritis. Hal penting dari pemikiran Simon adalah kritiknya atas reality program tentang betapa sulitnya sebenarnya kondisi kehidupan biasa (ordinary life) untuk kemudian sesuai dengan "standar" televisi. Oleh karena itu, untuk menyesuaikan dengan "standar" ini, dapat dipastikan konstruksi atas realitas terjadi. Selain itu, bagaimana televisi merefleksikan dunia nyata (concrete world) ke dalam teks media juga selalu ditentukan oleh beragam faktor, misalnya teknologi, ide-ide kreatif produsen, ekspektasi atau keinginan audiens, atau ekonomi media. Faktor-faktor ini, tentu saja, berpengaruh pada bagaimana realitas dikonstruksi, seperti apa prosesnya, bagian apa yang ditonjolkan, dan bagian mana yang tidak direpresentasikan.

Hal paling sederhana, misalnya, faktor fasilitas gedung yang digunakan untuk spektakuler show Indonesian Idol. Untuk musim pertama hingga kelima, Indonesian Idol menggunakan Balai Sarbini sebagai tempat spektakuler show, sementara untuk musim keenam menggunakan Central Park, dan musim ketujuh, menggunakan Studio 8 RCTI. Dari penggunaan gedung saja, konstruksi realitas dalam Indonesian Idol yang kemudian berpengaruh pada teks media yang disiarkan pada audiens mengalami perbedaan. Bentuk panggung pun berubah mengikuti gedung yang digunakan. Dari sini, dari faktor yang sangat sederhana, dapat berpengaruh terhadap proses konstruksi realitas.

Ketika ekonomi media menjadi faktor yang sangat menentukan dan dominan maka seluruh proses produksi, distribusi, dan konsumsi teks media akan selalu diarahkan pada akumulasi keuntungan (surplus value) atau pemasukan media. Oleh karena itu, yang kemudian menjadi "standar" dari proses konstruksi realitas adalah "layak jual" atau market price. Di sinilah, proses komodifikasi atas realitas berlangsung. Realitas yang dihadirkan dalam program Indonesian Idol pada akhirnya disesuaikan dengan pasar sehingga bukannya menghadirkan informasi sebagai upaya memenuhi kebutuhan informasi masyarakat (use value), tapi bagaimana memproduksi teks media (program) yang bisa dijual di pasaran dan mampu mendatangkan keuntungan (exchange value). Alih-alih meng-capture realitas yang sedang terjadi dengan apa adanya, pada dasarnya, apa yang dihadirkan pada audiens merupakan sebuah realitas yang telah dimanipulasi dengan disesuaikan pada kepentingan yang ingin dicapai. 
Orientasi ekonomi (profit) ini sangat jelas terlihat dari iklan Indonesian Idol, yaitu memiliki iklan utama untuk mendukung terselenggaranya program. Pada musim ketujuh, iklan utama Indonesian Idol adalah Cross Mobile, dan beberapa iklan utama-pendukung lain seperti Tolak Angin, Mie Sedap, Honda, Coolant Wardah, Bank Bukopin, Fiesta, dan MDS. Dalam tulisan ini, yang dimaksud iklan utama adalah iklan yang selalu disebutkan di sepanjang acara atau berupa video dari peserta yang menggunakan produk iklan tertentu di luar waktu siaran iklan komersial. Dengan adanya iklan utama, menjadi jelas bagaimana logika pasar masuk ke dalam proses produksi, distribusi, hingga konsumsi program Indonesian Idol. Ini berarti bahwa dengan menjadi iklan utama, dia turut menentukan bagaimana realitas dikonstruksi/dibentuk hingga kemudian dihadirkan pada audiens.

Pada akhirnya, apa yang ditampilkan di televisi hanyalah manipulasi realitas yang telah disesuaikan dengan berbagai faktor dan standar pada proses produksinya. Merujuk Baudrillard (1994), apa yang dilihat di televisi hanyalah simulasi belaka di mana realitas sendiri telah tergantikan oleh simulacra atau reproduksi objek atau peristiwa. Dengan kaburnya perbedaan antara tanda dan realitas, semakin sukar mengenali yang tulen dari barang tiruan. Baudrillard (dalam Ritzer \& Goodman, 2004: 642) memberikan contoh tentang bagaimana larutnya televisi ke dalam kehidupan dan larutnya kehidupan ke dalam televisi. Ini berakibat pada mana yang sebenarnya realitas dan mana yang bukan sangat sulit untuk dibedakan, atau dalam bahasa Baudrillard "a real without origin or reality". Kondisi seperti ini yang kemudian dilukiskan Baudrillard sebagai hyperreality, saat media berhenti menjadi cerminan realitas, tetapi justru menjadi realitas itu sendiri, atau bahkan lebih nyata daripada realitas itu. Dengan kata lain, ketika dunia dikuasai simulasi, simulasi menjadi realitas itu sendiri dan bahkan lebih nyata darinya. Maka yang tertinggal akhirnya hanyalah konstruksi atas realitas, yang dalam konteks Indonesian Idol, konstruksi tersebut disetir oleh standar "layak jual di pasaran (market price)".

\section{Fabricated Reality TV: It's All about Rating}

Saat realitas dalam Indonesian Idol dikonstruksi sedemikian rupa agar sesuai dengan standar market price dan menghasilkan marketable product, atau ketika logika ekonomi media seperti yang dirumuskan Alison Alexander (2004) mendominasi, maka untuk mencapai standar tersebut telah terjadi proses komodifikasi, di mana rating menjadi ukuran/patokan telah tercapai atau tidaknya standar tersebut. Ini bisa dilihat bahwa selama episode Spektakuler Show, rating Indonesian Idol selalu tinggi, selalu berada di peringkat antara 1-3. Market 
share yang dicapai pun tidak pernah di bawah 20\%, dengan angka paling rendah $21.3 \%$ dan tertinggi $26.2 \%{ }^{1}$

Dalam rangka melihat bagaimana proses komodifikasi terjadi, kembali merujuk pada Moscó (2009), perlu kiranya dilihat bagaimana relasi-relasi dalam proses produksi, distribusi, dan konsumsi. Dalam proses produksi, misalnya, akan melihat pilihan simbolsimbol yang digunakan dalam program Indonesian Idol sehingga mampu mewujud ke dalam sebuah program yang marketable (layak jual dan layak dipasarkan). Untuk mampu melihat bagaimana jalinan-jalinan di seluruh proses, baik produksi, distribusi, dan konsumsi, analisis akan melihat logikalogika atau alur atau apa yang direpresentasikan dalam program Indonesian Idol. ${ }^{2}$ Ini karena melalui logika-logika, alur, dan representasi akan diketahui bagaimana realitas dikonstruksi sehingga menjadi sebuah market product dan sesuai dengan market price.

\section{Logika Lomba: Ada Peserta, Talent, Juri, dan Pemenang}

Dengan dalih mencari orang dengan bakat menyanyi terbaik di

\footnotetext{
${ }^{1}$ Data rating diperoleh dari seorang teman yang bekerja di Dentsu Advertising Agency. Data rating adalah data resmi, namun untuk kepentingan karirnya, nama teman tidak dapat disebutkan dalam tulisan ini.

${ }^{2}$ Seluruh data mengenai Indonesian Idol selain berdasarkan pada pengamatan penulis di setiap episode Indonesian Idol musim ketujuh ini, juga beberapa data diambil dari situs resmi Indonesian Idol, http://www.indonesianidol.com/
}

Indonesia, masyarakat Indonesia sebagai target audiens digiring untuk memiliki keinginan akan lahirnya seorang Idola yang benar-benar berbakat yang mampu mengalahkan beribu-ribu orang lainnya dengan talent di bidang yang sama. Proses mencari Idola baru ini kemudian difasilitasi dengan keberadaan juri sebagai pihak yang menilai, memberikan komentar, dan juga memutuskan siapa yang berhak lolos selama proses audisi. Logika lomba seperti ini pada dasarnya memang merupakan sebuah logika yang dekat dengan masyarakat, misalnya, lomba-lomba 17 Agustus yang menjadi acara wajib di berbagai daerah dan kota di Indonesia untuk menyambut kemerdekaan. Setiap lomba biasanya selalu seru, menegangkan, dan sekaligus menyenangkan sehingga, dengan menggunakan logika lomba ini, audiens lebih mudah mencerna arah program dan membayangkan keseruan dalam mencari Idola baru Indonesia.

Selanjutnya, yang perlu dicatat dari logika lomba ini adalah bagaimana lomba yang dinamakan Indonesian Idol ini dikemas. Pertama, yang berhak menjadi peserta untuk program ini adalah semua masyarakat Indonesia dari daerah manapun. Semua yang berumur $16-27$ tahun dan merasa memiliki bakat dalam bidang menyanyi boleh mendaftar sebagai peserta. Dengan "seolah" melibatkan semua lapisan masyarakat Indonesia, program ini menjadi sebuah cara untuk meng-catch attention dari masyarakat 
tentang egaliternya program ini. Ini karena pada dasarnya tidak semua orang bisa mengikuti program ini karena permasalahan akses. Audisi hanya diselenggarakan di sembilan kota besar di Indonesia, yaitu Surabaya, Yogyakarta, Bandung, Manado, Ambon, Palembang, Medan, Padang, dan Jakarta. Meski akan ada banyak dalih tentang penyelenggaraan audisi hanya di kota-kota ini saja, tapi, di sisi lain, hal ini juga sekaligus tidak memberi kesempatan pada mereka yang tidak tinggal di sekitar kota-kota besar tersebut. Kedua, pilihan juri Indonesian Idol. Pada dasarnya, juri merupakan individu-individu yang telah sangat dikenal masyarakat sebagai musisi dan penyanyi. Agnes misalnya, telah dikenal semenjak dia masih artis cilik hingga kini yang membuktikan talentanya di bidang musik melalui berbagai prestasi dan penghargaan, ditambah lagi dengan proyek go international-nya, begitu juga Dhani dan Anang yang telah berpuluh tahun melanglangbuana di industri musik Indonesia dan terbukti telah melahirkan penyanyi-penyanyi besar Indonesia seperti KD dan Dewa 19. Juri-juri ini dipilih dengan beragam alasan. Salah satunya adalah mereka merupakan orangorang yang mengerti musik. Mereka adalah orang-orang dengan talenta musik yang telah terbukti mapan di industri. Singkatnya, mereka adalah orang yang memiliki kapasitas untuk menjadi juri. Tanpa menafikan jawaban tersebut, sebenarnya, ada banyak orang dengan kapasitas lebih, yang lebih mengerti musik, persoalan vokalitas, atau stage performance selain mereka. Misalnya, saja guru-guru vokal yang selama ini justru menjadi guru dari para penyanyi besar Indonesia. Namun, mereka bukanlah orang yang dikenal masyarakat. Mereka adalah orang-orang di balik layar yang tidak pernah disorot media sehingga ketika mereka dipilih sebagai juri Indonesian Idol, masyarakat akan bertanya-tanya siapa mereka. Masyarakat tidak familiar dengan orang-orang di balik layar sehingga ini akan mempersulit catching the audiences' attention yang nantinya itu bisa mengancam jumlah penonton Indonesian Idol dan berarti pula hal itu bisa mengancam rating.

Ketiga, dalam mencari pemenang keseruan dibentuk dengan proses audisi dan eliminasi yang panjang. Proses audisi dan eliminasi ini merepresentasi betapa sulit dan berlikunya jalan yang harus ditempuh oleh peserta untuk menjadi pemenang (Idola Indonesia). Ada empat tahap yang harus dilalui seorang peserta untuk menjadi pemenang. Tahap pertama adalah audisi yang diselenggarakan di beberapa kota besar Indonesia. Di tahap audisi ini, seorang peserta harus mendapatkan golden ticket untuk bisa melanjutkan ke tahap dua. Tahap dua adalah tahap eliminasi, yaitu mereka yang mendapatkan golden ticket disaring kembali hingga mengerucut pada 15 orang saja. Lima belas orang yang lolos tahap eliminasi masuk ke tahap Top 15 Show 
untuk kemudian disaring kembali menjadi 12 besar. Para peserta yang masuk ke dalam 12 besar berarti masuk ke tahap selanjutnya, yaitu Spektakuler Show. Di tahap Spektakuler Show, peserta akan dieliminasi satu-persatu di tiap minggunya, hingga di minggu ke 13 (The Result Show) terpilihlah seorang pemenang (Idola baru Indonesia).

Tahapan-tahapan tersebut merepresentasi perjuangan dari tiap-tiap peserta untuk bisa melewatinya. Tentunya, di setiap perlombaan, selalu menarik untuk melihat siapa yang nantinya akan keluar sebagai pemenang. Hal ini juga yang ditawarkan di Indonesian Idol. Setelah masuk Spektacular Show, misalnya, tiap-tiap peserta akan dibuatkan sebuah video yang berisi bagaimana perasaan mereka, tantangan yang mereka hadapi di minggu ini, apa kesulitan yang dihadapi, dan sebagainya yang akan ditayangkan pada para penonton tepat sebelum mereka mulai menyanyi. Tujuannya untuk menggalang dukungan dari para penonton, baik yang menonton langsung atau pun yang menonton melalui televisi di rumah, berupa vote SMS/telpon. Dukungan ini yang kemudian membedakan Indonesian Idol dengan logika lomba konvensional di mana juri memegang keputusan mutlak. Dukungan melalui vote SMS/telpon ini yang nantinya menentukan siapa yang tereliminasi di tiap minggunya dan pada akhirnya siapa yang menjadi pemenang.
Performance, Tata Panggung dan Kesan

Selain logika perlombaan yang dikemas sedemikian rupa seperti dijelaskan di atas, kemudian perlombaan itu sendiri dikemas pun adalah proses yang penting. Perlombaan yang akan dibahas di sini adalah pada tahap Spektacular Show karena di tahap inilah program Indonesian Idol ditayangkan secara langsung (live) dan menjadi tahap yang paling utama dari seluruh proses audisi. Spektacular Show pada dasarnya merupakan tahapan di mana perlombaan berlangsung. Ada banyak cara untuk menyajikan sebuah perlombaan menjadi menarik untuk ditonton dan terus diikuti, dan dalam case Indonesian Idol, tata panggung, lighting, sound system, pengambilan gambar, musik pengiring, LED screen, busana dan make up peserta, dan para penonton yang berada di studio adalah proses konstruksi terhadap realitas lomba agar menarik dan mampu meraup banyak penonton.

Penampilan peserta kemudian tidak hanya disokong oleh musik semata yang menjadi supporting system utama dalam perlombaan menyanyi, tetapi juga disokong oleh banyak faktor yang turut menentukan kesan penampilan seorang peserta. Kesan ini kemudian menjadi penting karena akan menentukan vote SMS/telpon terhadap seorang peserta. Misalnya saja, lighting yang digunakan yang menambah kesan mewah, anggun, atau ceria atau cara pengambilan gambar 
(angle) selama tayangan berlangsung dan apa yang ditayangkan akan menentukan apa yang ditonton oleh penonton di rumah dan ini juga turut menimbulkan kesan-kesan tertentu bagi penonton.

\section{Keterlibatan Audiens: Vote atau} Idola Tereliminasi

Seperti telah disinggung sepintas pada bagian sebelumnya, dalam Indonesian Idol, ada logika dukungan yang dipakai. Dukungan berupa vote melalui SMS atau telpon untuk tiap peserta tertentu. Untuk vote melalui SMS bisa dikirimkan dengan mengetik nama peserta yang didukung dan dikirimkan ke 6288 dengan tarif 2000/pes SMS. Sementara dukungan telpon, para peserta bisa menelpon operator dengan nomer yang ditentukan selama perlombaan. Nomor yang dituju disesuaikan dengan nomor urut tampil peserta. Dukungan dari para audiens baru bisa digunakan di Spektakuler Show. Sebelum Spektakuler Show, semua keputusan berada di tangan juri.

Adanya logika dukungan ini seolah menempatkan audiens sebagai pihak yang memilih dan menentukan siapa the next Indonesian Idol. Dengan menciptakan keterlibatan audiens selama program Indonesian Idol, hal ini sekaligus mengikat audiens untuk terus menonton Indonesian Idol, yang pada akhirnya akan menentukan rating Indonesian Idol dan juga pemasukan yang diterima pihak media penyiar. Dari dukungan ini, ketika kita membawa pada persoalan ekonomi politik media, maka ada pemasukan/keuntungan lain yang tidak hanya diperoleh media dari pemasukan iklan semata. Namun, juga dari tarif SMS dan telpon yang dikenakan pada setiap SMS/telpon yang masuk dimana tarif tersebut seluruhnya ditanggung oleh audiens (pengirim SMS dan penelpon) namun kemudian masuk sebagai salah satu pemasukan dari program Indonesian Idol.

Dukungan audiens ini yang disebut Moscó bahwa dalam setiap proses komodifikasi, yaitu proses perubahan teks media menjadi exchange value dan upaya perpanjangan surplus value selalu bergantung pada banyak faktor, termasuk salah satunya adalah konsumen (audiens). Mosco menuliskan, "The extent of surplus value realization depends on numerous factors, in labor, consumers, and capital market” (Moscó, 2009: 134). Pada akhirnya, apakah proses komodifikasi telah berhasil dan tercapai akan ditentukan oleh konsumen (audiens).

\section{Promosi Iklan yang Subtle}

Iklan, sebagai salah satu pemasukan utama media, merupakan hal yang sentral dalam kritik ekonomi politik media. Ini karena seluruh proses produksi, distribusi, dan konsumsi seluruhnya pada akhirnya hanya mengacu pada bagaimana iklan selalu datang. Komodifikasi terhadap realitas, bagaimana realitas yang dimunculkan 
dalam program Indonesian Idol merupakan sebuah konstruksi sedemikian rupa agar menjadi sebuah marketable product pun ujung-ujungnya hanyalah untuk terus mengikat iklan yang ada dan terus menarik iklan-iklan lainnya agar terus berdatangan. Oleh karena itulah, posisi iklan begitu sentral dalam menentukan arah produksi program, atau distribusi hingga konsumsi. Dalam Indonesian Idol, iklan pun sangat menentukan bagaimana program diproduksi hingga dikonsumsi oleh audiens. Sentralnya posisi iklan ini direpresentasi ke dalam promosi produk dengan cara yang cukup halus, yaitu dengan melibatkan para peserta (yang selama program Indonesian Idol berlangsung memiliki penggemar/ pendukung tetap dan bahkan setia). Biasanya siaran tentang iklan ini akan dimunculkan di segmen terakhir sebelum iklan komersial dimulai.

Iklan biasanya akan menggunakan setting keseharian para peserta. Misalnya, di ruang tamu asrama peserta, dua atau tiga peserta sedang sibuk dengan handphone masing-masing. Lalu, satu di antara mereka mengeluhkan betapa sedikitnya fasilitas yang dimiliki handphone-nya sehingga dia tidak bisa bermain-main. Dua peserta lainnya kemudian akan menganjurkannya untuk mengganti handphone miliknya dengan handphone merk Cross. Promosi-promosi seperti ini yang biasanya ditayangkan kepada para audiens. Produk yang dipromosikan oleh para peserta biasanya juga iklan-iklan utama dari Indonesian Idol.

Tidak hanya video promosi produk seperti disebut di atas, iklan utama juga sangat menentukan dan mengatur apa saja yang perlu diucapkan host acara selama siaran berlangsung. Di setiap pembukaan acara, apakah itu di awal atau di setiap selesai jeda iklan komersial, atau di akhir segmen menuju iklan komersial atau pada penutupan acara, host akan selalu menyebutkan iklan utama di dalamnya. Misalnya, "kembali lagi di Indonesian Idol yang dipersembahkan oleh Cross Mobile.." atau "tetap di Indonesian Idol, dipersembahkan oleh Cross Mobile, it's your pride..”.

Relasi-relasi kuasa seperti yang dijelaskan di atas, tentang bagaimana pemilihan juri, realitas mana yang dikedepankan, dan seperti apa realitas dibentuk, bagaimana iklan diposisikan dalam program merupakan relasi-relasi yang disebut Moscó menentukan proses komodifikasi atas content (teks) media hingga akhirnya program Indonesian Idol menjadi teks media yang layak jual dan mampu menarik banyak penonton sehingga mendapatkan rating tinggi dan kemudian mendapatkan pemasukan besar melalui iklan yang itu berarti adalah keuntungan (surplus value) terhadap media yang menyiarkan, yaitu RCTI. Realitas yang dihadirkan di televisi pun pada akhirnya adalah hasil konstruksi dengan maksud komodifikasi atasnya, 
inilah yang disebut Hill (2007: 140) sebagai fabricated reality.

\section{Rating Tinggi Indonesian Idol= (BUKAN) Keuntungan RCTI}

Seperti dapat dilihat di atas, persoalan ekonomi politik media dan bagaimana relasi kuasa di dalamnya tidak pernah bisa dilepaskan dari persoalan kepemilikan (ownership) media tersebut. Dalam kasus Indonesian Idol, secara eksplisit, dapat dikatakan bahwa pundipundi keuntungan yang diperoleh dari komodifikasi realitas akan masuk pada pemilik RCTI sebagai media yang menyiarkan. Namun, dalam perspektif yang lebih luas, keuntungan tidak berhenti hanya pada (pemilik) RCTI. Ini karena Indonesian Idol sendiri merupakan program yang diproduksi berdasarkan kerjasama dengan Fremantle Media, yaitu perusahaan produser program televisi. Ini berarti bahwa keuntungan dari program Indonesian Idol melalui komodifikasinya atas realitas juga mengalir pada Fremantle Media.

Fremantle Media sendiri merupakan perusahaan produser program televisi (content business production) terbesar di dunia. Produksinya mencakup serial drama, entertainment \& reality show, game show, dan komedi yang terdistribusi di 43 negara seperti Inggris, Amerika Serikat, Australia, Indonesia, Jerman, Belanda, dan banyak lagi. Fremantle Media bekerja dengan cara menjual konsep program sekaligus bantuan produksi untuk programprogram yang dimilikinya. Di Indonesia, Fremantle Media memiliki partner lokal PT. Dunia Visitama Produksi. Lembaga ini yang kemudian juga involve dalam pengerjaan produksi Indonesian Idol. Selain Indonesian Idol, program-program lain dari Fremantle Media yang tayang di Indonesia adalah Master Chef, Take Me Out, dan Indonesia's Got Talent. ${ }^{3}$ Sementara itu, mengenai kepemilikan Fremantle Media dan dari mana asal perusahaan ini, Fremantle Media adalah anak perusahaan dari RTL Group, yaitu perusahaan jaringan entertainment terbesar di Eropa. RTL Group membawahi 46 stasiun televisi dan 29 stasiun radio di sembilan negara sekaligus produksi program di hampir seluruh dunia. RTL Group terpusat di Inggris, namun memiliki banyak cabang di negara-negara lain khususnya Eropa. Saham RTL Group sebesar 92.3\% dimiliki oleh Bertelsmann AG, sementara saham sisanya sebesar 7.7\% diperdagangkan secara publik di Brussels dan Luxembourg. 4

\footnotetext{
${ }^{3}$ Data tentang Fremantle Media dirangkum dari situs resmi Fremantle Media, http://www.fremantlemedia.com/Production.aspx, http://www.fremantlemedia.com/Production/Who We Work With.aspx,

http://www.fremantlemedia.com/Production/Our Brands.aspx,

http://www.fremantlemedia.com/Production/Our Brands/Idols.aspx,

${ }^{4}$ Data kepemilikan saham diambil dari situs resmi RTL Group yang dapat diakses di http://www.rtlgroup.com/www/htm/profile.aspx dan di situs resmi Fremantle Media http://www.fremantlemedia.com/About Us/Struc ture.aspx
} 
Sederhananya, kepemilikan Fremantle Media jika digambarkan akan seperti ini:

\section{BERTELSMANN}

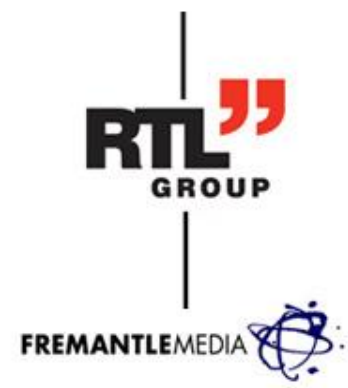

Dengan logika kepemilikan seperti di atas, maka keuntungan terbesar akan masuk ke kantong Bertelsmann AG sebagai pemilik saham terbesar di RTL Group yang menjadi induk perusahaan dari Fremantle Media, dan bukannya RCTI. Urutannya, Fremantle Media memiliki ide program yang dijual ke banyak negara, yaitu program "Idol" (di Indonesia menjadi Indonesian Idol, di Amerika menjadi American Idol). Penjualan ini juga sekaligus membantu produksi program melalui partner lokal yang dimiliki Fremantle Media. Ketika rating Indonesian Idol tinggi, pemasukan terhadap media penyiar pun besar. Namun sebenarnya, selain ada yang dishare oleh RCTI pada Fremantle Media sebagai pihak yang memiliki ide otentik program berupa pembelian ide program, rating yang dicapai program Idol di Indonesia (Indonesian Idol) adalah materi yang kemudian "dijual” oleh Fremantle Media pada negara-negara lain untuk terus memproduksi program-program yang lahir dari rahim Fremantle Media.

Contoh paling sederhana adalah Indonesian Idol. Acara ini terus diadakan tiap tahunnya karena rating yang tinggi. Keberlanjutan program tentu saja berarti keberlanjutan kerjasama antara RCTI dan Fremantle Media, dan itu juga berarti keberlanjutan kontrak antara keduanya (ini berarti pemasukan terhadap Fremantle Media). Contoh lainnya, semakin banyak program-program yang diproduksi berdasar program Fremantle Media seperti Master Chef dan Take Me Out. Semakin tinggi jumlah programprogram asal Fremantle Media yang diproduksi, maka akan semakin besar pula keuntungan di pihak Fremantle Media (Bertelsmann AG). Merunut logika ini, maka dapat dikatakan bahwa konstruksi realitas dalam Indonesian Idol yang bertujuan untuk komodifikasi, pada akhirnya hasil terbesar dari proses komodifikasi tersebut jatuhnya justru bukan pada RCTI sebagai media siarnya, tapi pada Fremantle Media (RTL Group) dan ujung-ujungnya bermuara pada Bertelsmann AG.

\section{Kesimpulan}

Tulisan ini mengkaji program realiti Indonesia Idol dengan perspektif ekonomi politik. Hasil kajian menunjukkan bahwa Indonesia Idol merupakan bagian dari proses komodifikasi content yang diorientasikan untuk memaksimalkan keuntungan 
televisi, dalam hal ini RCTI. Komodifikasi content itu dilakukan melalui beragam cara, diantaranya setting panggung, pilihan juri, ataupun format lomba dalam Indonesian Idol. Keseluruhan komodifikasi itu pada akhirnya menguntungkan industri televisi, dalam hal ini RCTI dan lebih-lebih Fremantle Media yang merupakan penggagas program siaran tersebut.

\section{Daftar Pustaka:}

Alexander, Alison (ed.). 2004. Media Economics: Theory and Practice. Third Edition. New Jersey: Lawrence Erlbaum Associates.

Baudrillard, Jane. 1994. Simulacra and Simulation. Ann Arbor: University of Michigan Press.

Golding, Peter dan Graham Murdock. $1992 . \quad$ 'Culture, Communications, and political Economy.' Dalam Curran, James and Michael Gurevitch (ed). Mass Media and Society. London: Edward Arnold.

Hill, Annette. 2005. Reality TV: Audiences and Factual Popular Television. New York: Routledge.

. 2007. Restyling Factual TV: Audiences and News, Documentary and Reality Genres. New York: Routledge.

Mosco, Vincent. 2009. The Political Economy of Communication. Second Edition. London: Sage Publications.

Ritzer, Geroge \& Douglas J. Goodman. 2004. Teori Sosiologi Modern (terj.). Edisi Keenam. Jakarta: Prenada Media.

\author{
Simon, Ron. 2005. "The Changing \\ Definition of Reality \\ Television". dalam Gary R. \\ Edgerton \& Brian G. Rose \\ (ed.). Thinking Outside The \\ Box: A Contemporary \\ Television Genre Reader. \\ Kentucky: University Press of \\ Kentucky.
}

Situs:

http://www.indonesianidol.com/, diakses pada tanggal 7 Juni - 7 Juli 2012.

http://www.fremantlemedia.com/Product ion.aspx, diakses pada tanggal 10 Juli 2012.

http://www.fremantlemedia.com/Product ion/Who We Work With.as px, diakses pada tanggal 10 Juli 2012.

http://www.fremantlemedia.com/Product ion/Our Brands.aspx, diakses pada tanggal 10 Juli 2012.

http://www.fremantlemedia.com/Product ion/Our Brands/Idols.aspx, diakses pada tanggal 10 Juli 2012.

http://www.rtlgroup.com/www/htm/prof ile.aspx, diakses pada tanggal 10 Juli 2012.

http://www.fremantlemedia.com/About Us/Structure.aspx, diakses pada tanggal 10 Juli 2012. 
Jurnal Komunikasi, Volume 11, Nomor 1, Oktober 2016 